\title{
THE WATER METABOLISM OF NEWBORN INFANTS AND ANIMALS ${ }^{\star}$
}

\author{
BY \\ H. HELLER \\ From the Department of Pharmacology, University of Bristol \\ (Received for Publication Octoper 3, 1950)
}

Clinical experience leaves no doubt that the water metabolism of infants differs from that of normal adults. This difference emerges not only from the well known facts that an apparently small decrease of fluid intake or increase of the fluid loss may produce clinical symptoms of dehydration, but it is also evident from the ease with which oedema may be produced by ' therapeutical ' administration of fluids to newborn children.

In practice dehydration in infants mainly seems to occur in two conditions. First, where a normal intake of food is not balanced by a sufficient intake of water (Rietschel, 1934; Finkelstein, 1938). Secondly, when diarrhoea and vomiting lead to excessive losses of fluid and certain electrolytes.

Dehydration undoubtedly remains the chief cause of the continued high fatality rate in cases of infantile diarrhoea and vomiting. Its prevention or early correction constitutes the most important factor influencing recovery. However, the therapeutic problem in cases of dehydration is clearly not a simple one: the amount and composition of the fluid to be given and the route of administration require careful consideration and if, as may be necessary, intravenous application has to be chosen, the rate of infusion will also need to be watched carefully. Decisions as to therapeutic measures covering these factors have frequently still to be made on empirical grounds. It is therefore not surprising that instances of gross cedema are observed (Arnott and Young, 1942; Alexander, 1948). Death in infants after intravenous administration of fluids has also been ascribed to cardiac failure due to overloading of the circulation (Alexander, 1948).

Water depletion and salt depletion will have to be kept apart as in adults but it is clear that more knowledge of the water metabolism of infants is required. The analysis of the effects of dehydration and rehydration in adults forms the necessary basis for such studies, but it would clearly be a serious

- A lecture given in the Department of Paediatrica, Harvard University, during the tenure of a visiting professorship at New York University Medical School. mistake to apply the results of work on adults unreservedly to newborn infants. It is equally evident that investigators concerned with a comparison between the water metabolism of infants and of adults will have to consider a variety of factors which are either known, or which may be suspected to operate differently in the newborn. These differing factors may be grouped as follows: ( $a$ ) differences in the internal environment of the newborn, i.e. differences in the solute composition and the relative volumes of the extra and intracellular fluid phases, (b) differences in renal development and function, (c) differences in the functional state of integrative structures, namely of the endocrine glands and the hypothalamic structures which regulate or influence the metabolism of water and the electrolytes. Some of these factors and their interplay can and have been studied in infants. However, the limitations inherent in clinical investigations necessitate in many instances recourse to animal experiments.

A certain amount of preliminary but very valuable and interesting work on animals was done by continental investigators, notably by Kerpel-Fronius (1932). This work has been much expanded during recent years, thanks mainly to the stimulus given by the development of the renal clearance techniques by $H$. W. Smith and the clinical investigations of McCance and his co-workers. It is therefore proposed to discuss some of the recent results obtained in newborn mammals and to compare the findings so far as possible with those in newborn infants. It may be well to emphasize in this connexion that results obtained in newborn animals should not be regarded as complementary to findings in newborn infants, even if the conditions under which they were obtained are reasonably comparable. This necessity arises less from species differences in the regulatory mechanisms and effector systems concerned than from species differences in the maturity at birth. Newborn rats, for example, are markedly less mature at birth than newborn children; newborn guinea-pigs, on the other hand, are, according to most criteria, considerably further developed than either. These differences in maturity 
have perhaps certain advantages for the experimental worker. When we decided some years ago to study certain aspects of the water metabolism in newborn mammals, newborn rats were deliberately chosen because it was hoped that any deviations from the adult would be more easily recognizable in such immature animals. It is interesting to note that quite independently newborns of the same species were selected by the Cambridge workers (McCance and Wilkinson, 1947).

The primary function of the mechanisms which regulate the water metabolism of animals consist in keeping the body water constant within narrow bounds. This implies that the organism is able to eliminate extra water in a comparatively short time and, on the other hand, that the internal environment remains intact even though water intake is intermittent and renal and extrarenal loss continuous.

It was therefore decided to investigate first how newborn rats react to an alimentary water load which is easily and quickly disposed of by adult animals (Heller and Smirk, 1932a), and secondly to study the response of the newborn rats to degrees of dehydration which, as regards their internal environment, are well compensated by adult rats by means of their highly developed osmoregulatory mechanisms.
The first problem centres on the question whether newborn animals exhibit an adult type of water diuresis. It was found (Heller, 1947a) that the response of newborn rats differs markedly from that of adults. When $4.5 \mathrm{~g}$. water $/ 100 \mathrm{~g}$. were placed in the stomach of rats aged 24 to 48 hours and the urinary output was measured for the following 5 hours, no evidence for an increase of urinary output could be obtained (Fig. 1). The method of urine collection used in these experiments was not sufficiently accurate to be certain that a response to water administration was entirely absent; micturition in newborn rats is not spontaneous and urine output had to be determined by averaging the weight of urine contained in the bladder of series of animals killed at given times after water administration. However, it is sufficiently clear that any increases of urine volume must have been very small at best. It should be mentioned here that the newborn rats in which these results were obtained were kept at an environmental temperature of approximately $31^{\circ} \mathrm{C}$. This temperature was chosen because full capacity for thermoregulation is only acquired by rats during the fourth week of extrauterine life (Brody, 1943). Newborn rats derive much of their warmth from the mother, i.e. from the contact with a surface of about $31^{\circ} \mathrm{C}$. (Herrington, 1940). It did, therefore, seem to be

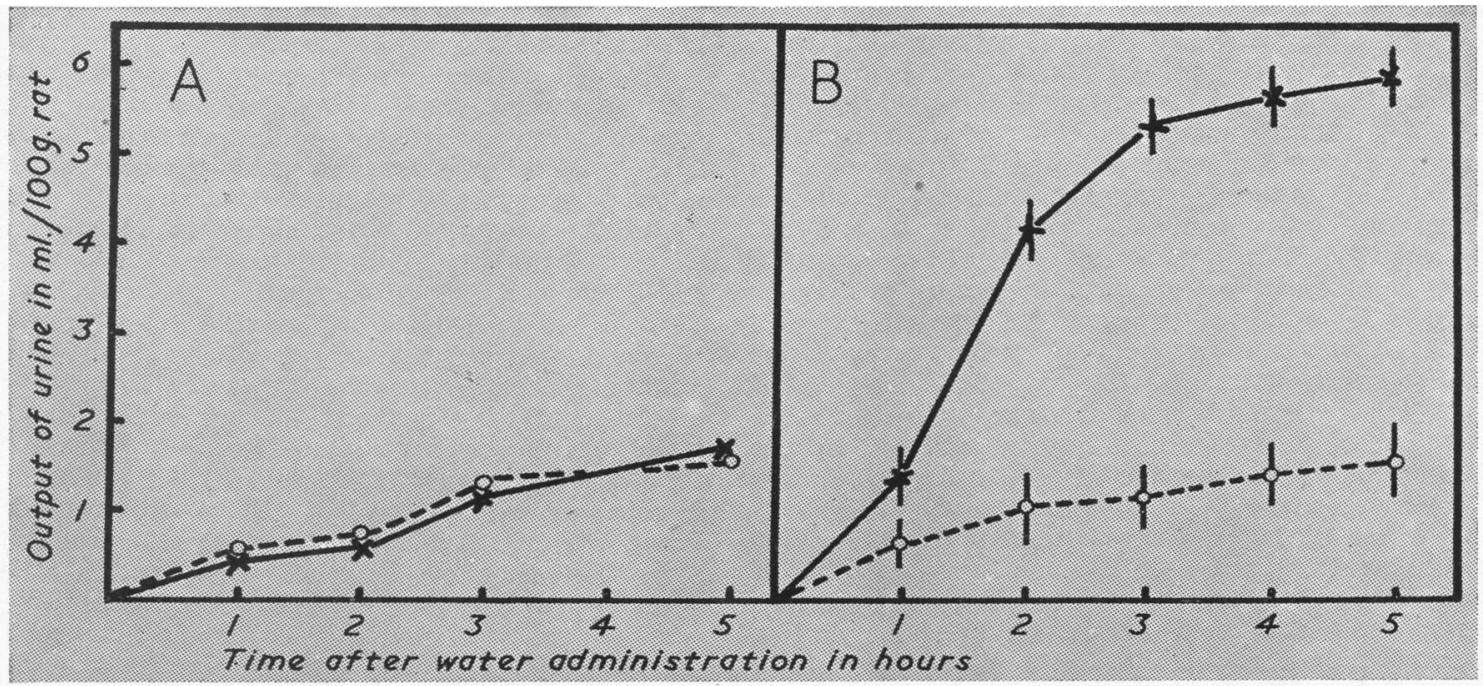

A. $\mathrm{X}-\mathrm{X}=$ mean urinary output of newborn rats after the intragastric injection of $4.5 \mathrm{~m} 1$. water $/ 100 \mathrm{~g}$. rat.
B. $\mathrm{X}-\mathrm{X}=$ mean urinary output of adult rats which received $4.5 \mathrm{ml}$. water $/ 100 \mathrm{~g}$. by mouth. $\mathrm{O}---\mathrm{O}=$ controls
$\mathrm{O}-\mathrm{O}=$ controls. The vertical lines indicate the standard error.

Fig. 1.-Comparison between the urinary output of newborn and of adult rats after administration of water by the stomach (Heller, 1947a). 


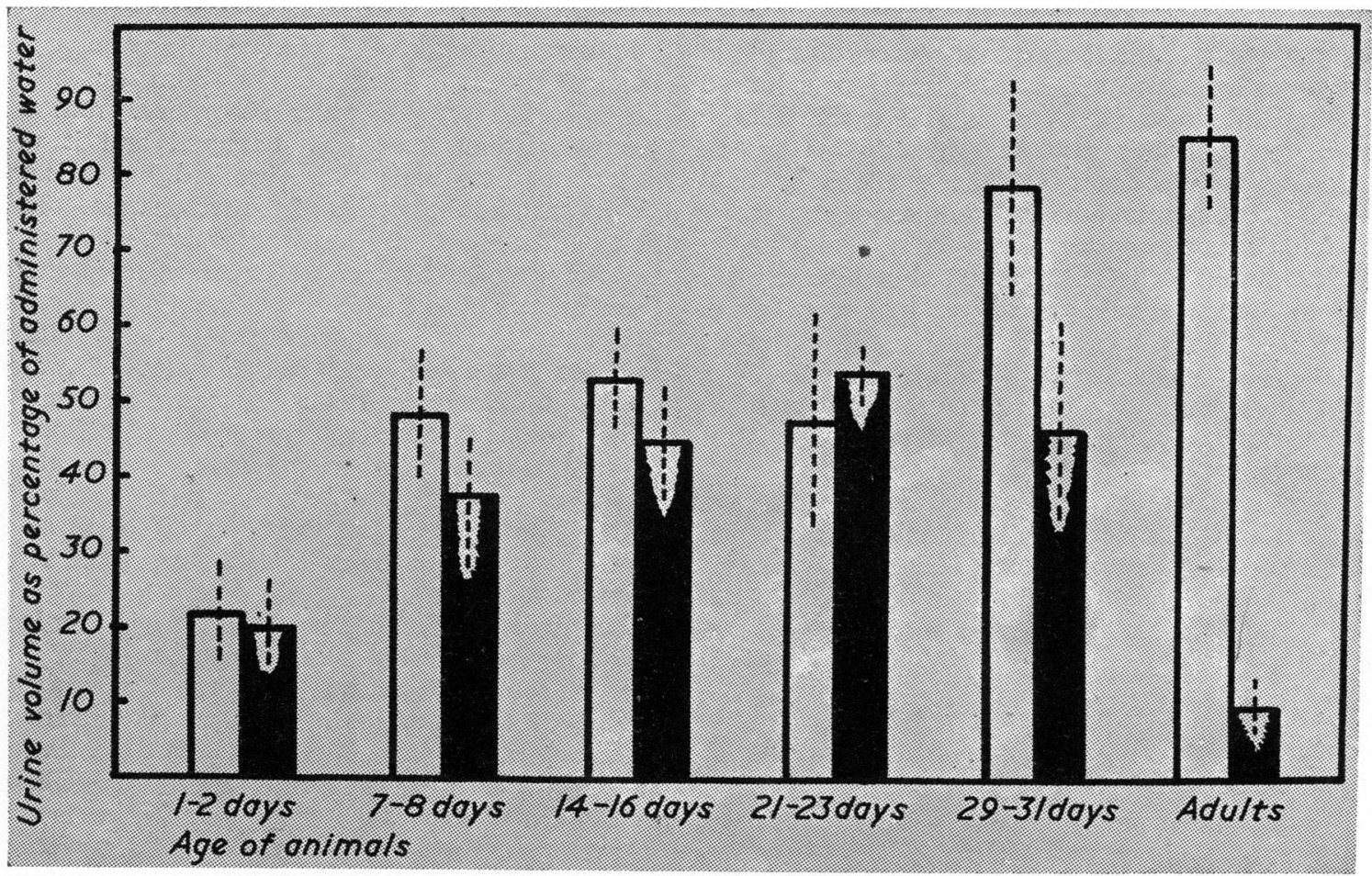

mean urine volume of urine 145 minutes after the administration of $4.5 \mathrm{ml}$. water/100 g. by stomach tube

mean urine output of litter mates 145 minutes after the same amount of water and the injection of $10 \mathrm{~m} U$ vaso-pressin/100 g. rat. The broken lines indicate twice the standard error of the mean.

Fig. 2.-Development of the response to water administration and to the injection of posterior pituitary antidiuretic hormone in rats. It will be noted that only in the rats aged 4 weeks the urine volume approximated to that of the adult animals, a small but significant anti-diuretic response to the posterior pituitary hormone was found in rats of the same age (Heller, unpublished experiments).

more advisable to conduct ' physiological' experiments at about $31^{\circ} \mathrm{C}$. than at room temperature which would lead to considerable undercooling. However, it has been shown by Heller and Smirk (1932b) that keeping adult rats at raised environmental temperatures leads to an inhibition of water diuresis which is not due to the increased extrarenal water loss. Was the failure to obtain water diuresis in newborn rats caused by an unduly high temperature? Experiments done on newborn rats kept at lower air temperatures excluded this possibility. On the contrary, they revealed the remarkable fact that the urinary output increased markedly with a rise of environmental temperature: newborn rats at $20 / 21^{\circ} \mathrm{C}$. excreted a mean of $0.52 \mathrm{ml} . / 100 \mathrm{~g}$. in four hours; newborn rats at $30 / 31^{\circ} \mathrm{C}$. excreted $1.23 \mathrm{ml} . / 100 \mathrm{~g}$. in four hours. Similar findings have been made in frogs (Krause, 1928), but it was surprising to find this feature in a mammalian species. It can be concluded from these results that the virtual absence of water diuresis in our series of newborn rats was not due to heat inhibition.
McCance and Wilkinson (1947) found similarly that newborn rats were unable to excrete administered water, that the minute volume of urine rose slightly in animals aged four days and that it increased considerably in rats aged 12 days. It will be seen from Fig. 2, which compares the response of adults with that of rats aged from 1 to 28 days, that adult values are reached during the fourth week after birth.

How do rats compare in this respect with the newborn of other mammalian species? The results of Adolph (1943) on puppies indicate that an incompletely developed ability to reduce an excess water load by the renal route is not restricted to newborn rats, and an investigation of the renal function of newborn guinea-pigs which has recently been completed (Dicker and Heller, 1951) shows that the same applies to this species. Guinea-pigs, as already mentioned, are by all available criteria much more mature at birth than rats. (The incisors of rats, for instance, erupt only after eight to 10 days of extra-uterine life, whereas in the guinea-pig they 
are present at birth.) It is in keeping with these developmental differences that water diuresis in newborn guinea-pigs is already quite pronounced though administered water is still excreted at a considerably lower rate than by adults (Fig. 3). Judging from the scanty evidence available it would appear that infants show the adult response to water administration comparatively late: Aschenheim (1919) and Lasch (1923) found that infants aged up to 3 months of age excreted a dose of water given by mouth at a much slower rate than babies in the second half year of life. It is clear, however, that these results will have to be repeated in more closely defined age groups and with adequate adult controls.

Why is water diuresis less well developed in the newborn than in the adult? Many factors which are known to influence the course of a water diuresis have still to be investigated before this question can be answered. However, some indications of the

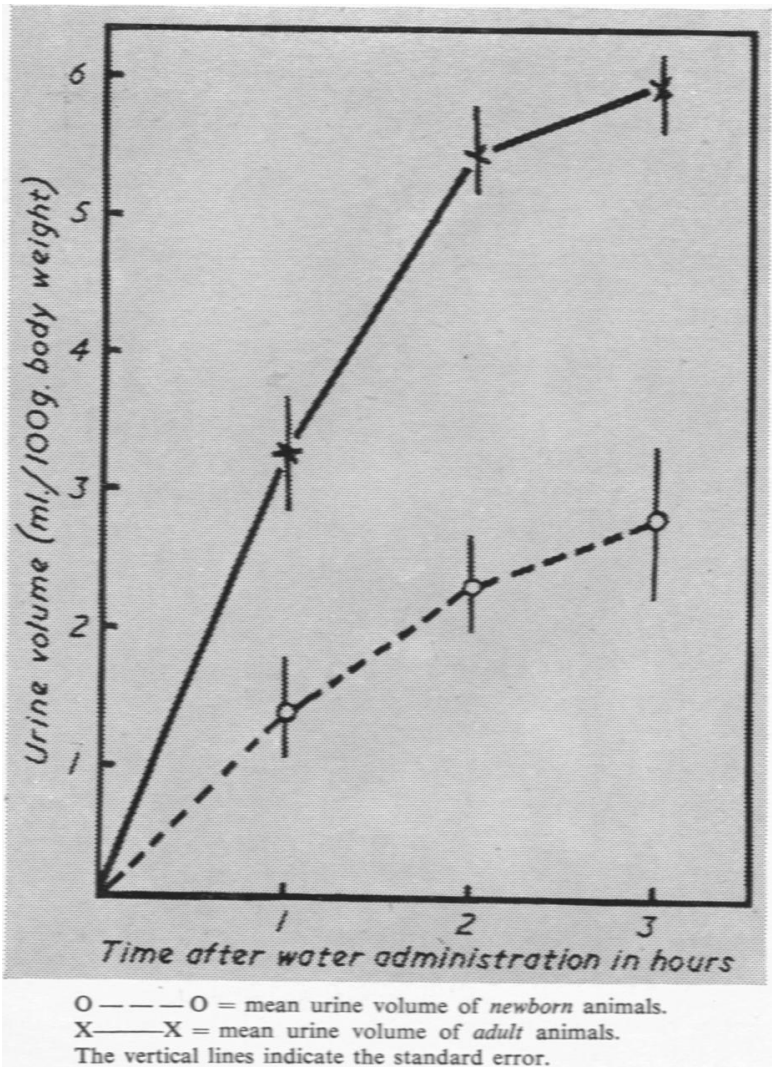

FIG. 3.-Comparison between the urinary output of adult and of newborn guinea-pigs after the administration of $5 \mathrm{ml}$./water/100 $\mathrm{g}$. body weight by mouth (Dicker and Heller, 1951). different manner in which newborn mammals handle administered water were obtained from our comparison between adult and newborn rats. For instance, the rate of water absorption from the gastro-intestinal tract was measured and it was found that newborn rats absorbed water more slowly than adult animals of the same strain. This delay in the alimentary water absorption which may be due to adrenal cortical or anterior pituitary hypofunction (Clark, 1939; Gaunt, 1944; Joseph, Schweizer, Ulmer, and Gaunt, 1944) would by itself lead to some decrease in the rate of water excretion. However, it could be shown that this is only a minor factor which modified water diuresis in the newborn animals. Further investigation indicated that the newborn rats were unable to excrete 'extra water' at the adult rate even after absorption from the gastro-intestinal tract had been completed.

Determinations of the rate of extrarenal water loss revealed that newborn rats kept at $20 / 21^{\circ} \mathrm{C}$. (i.e. at room temperature) lost much less water extrarenally than adults at the same temperature. Newborn rats kept at $30 / 31^{\circ} \mathrm{C}$., lost water extrarenally at about the same rate as adult animals at $20 / 21^{\circ} \mathrm{C}$. These results show that the extrarenal loss during the five hours after water administration cannot account for the virtual absence of water diuresis, and since alimentary water absorption in the newborn rats was shown to be completed in about three hours and the urine volume hardly increased during this time, it follows that any of the administered water residual after this period was lodged in the extra-alimentary tissues. In a series of newborn rats kept at $30 / 31^{\circ} \mathrm{C}$. for instance, this residual or tissue water load after three hours amounted to about $70 \%$ of the dose administered and to about $60 \%$ five hours after the water had been given. In other words, a dose of water which, owing to the quick alimentary absorption and renal excretion, increases the tissue water load of adult rats slightly and for a short period only (Heller and Smirk, 1932a) led to a state of ' cedema' in normal newborn rats. It remains to be seen whether the residual water is uniformly distributed in the tissues of the newborn rats or whether the oedema is localized as after water administration to hypoproteinaemic rats with an already expanded extracellular fluid space whose water metabolism resembles in many ways that of the normal newborn animals (Dicker, 1950). These findings in rats may prove of some interest in connexion with the comparative frequency with which oedema after parenteral administration of fluid has been observed in newborn infants. A comparison between the response of adults and infants to the same relative 
extra water load may show that the factors which operate in newborn rats contribute-though perhaps to a minor degree-to the occurrence of oedema in the newborn child.

However, judging from a report of Gaisford and Schofield (1950) a distinction may have to be drawn between premature infants and those delivered at term. Premature infants, according to the experience of these authors, stand withdrawal of fluid for the first three or four days after birth comparatively well. This may be partly due to the well known fact that many premature babies show signs of oedema at birth. Gaisford and Schofield, for instance, observed oedema in $9 \%$ of their cases, and the incidence in Hallum's (1941) series was as high as $13.4 \%$ in contrast to $1.2 \%$ in children born at or near full term. It may be assumed from similar findings in cases of oedema of malnutrition (Dicker, 1948) that the occurrence of 'visible' oedema corresponds to a far larger number of cases in which the extracellular fluid space is abnormally increased even though the oedema is not clinically recognizable. A beneficial effect of fluid restriction in infants suffering from visible or occult oedema can thus be postulated when fluid and food are withdrawn for a short period; the measure would act as a stimulus for the excretion of extra body water. A similar effect has frequently been observed in this laboratory: animals suffering from an expansion of the extracellular fluid space due to protein deficiency frequently showed, when deprived of water and food, a paradoxical djuresis; in other words, they excreted oedema fluid (Dicker, Heller, and Hewer, 1946). Different effects may be expected when fluid losses occur in full term infants and animals. The size of their fluid compartments is probably optimal and losses of body water are therefore likely to lead to abnormalities of the internal environment.

To compare the effects of dehydration in adult and newborn rats fluids and food were withdrawn from both series of animals for 24 hours, and the environmental temperature of the newborns was so adjusted that their extrarenal water loss approximated to that of the adult animals. The results of the experiments (Heller, 1949) showed that adult rats responded to the withdrawal of water (and food) for $\mathbf{2 4}$ hours in much the same manner as human adults (Nadal, Pedersen, and Maddock, 1941) and adult dogs (Elkinton and Taffel, 1942; Elkinton and Winkler, 1944). The urines excreted at the end of the period of water deprivation were-as one could expect-highly concentrated. The mean urine volume fell from 10.6 to $1.5 \mathrm{ml} . / 100 \mathrm{~g}$. in 24 hours. The mean extrarenal water loss was high $(5 \cdot 5 \pm 0.20 \mathrm{~g} . / 100 \mathrm{~g}$. in 24 hours $)$ which is in accordance with the relatively large body surface of the small species investigated. The obligatory expenditure of water (made up of the amounts lost from skin, lungs, and the alimentary tract and the volume needed for the adequate excretion of solutes in the urine) must clearly have made demands on the extracellular fluid of animals whose only source of fluid consisted in the metabolic water derived from body reserves. However, not only was the normal ionic composition of the plasma on the whole maintained, but the extracellular fluid volume and particularly the plasma volume were also well defended: no marked increase in plasma solids and little change in the haematocrit and the red cell counts were found after 24 hours of dehydration. In view of the magnitude of the total water loss, the avoidance of haemoconcentration can only have been achieved by a shift of intracellular water. An increase in the renal excretion of the intracellular electrolyte potassium was observed in the dehydrated adults, which is in agreement with this conclusion. The plasma potassium level of the dehydrated adults was not significantly raised. Similarly, a decrease of cell potassium without an increase in plasma potassium has recently been demonstrated by Elkinton, Winkler, and Danowski (1948) in adult dogs deprived of water.

It would then seem that in adult rats the renal functions involved in the balancing of fluid losses after 24 hours of dehydration consist in an adequate ability to clear surplus crystalloids from the plasma, and it seems likely that one of the mechanisms concerned in this is a relatively unimpaired rate of glomerular filtration: no significant rise of the plasma urea, such as would occur with a substantial decrease of glomerular filtration (Gamble, 1947), could be found in the adult animals. The other renal activity concerned in this 'defensive' process is the tubular function of concentrating the urine to hypertonic levels.

How do newborn rats deprived of fluid and food for 24 hours differ in their response from that of adult animals? It could first be shown that the concentration of the urine increased much less than in the adults. Estimations of the urine/plasma ratios of chloride, sodium, potassium, and urea agreed with this finding. More water per unit weight of urinary solids was therefore excreted by the newborn rats but the difference between the 24-hour urine volumes of the dehydrated newborns and adults proved to be smaller than expected. This suggests that, in newborn rats which have been deprived of fluid for a comparatively short time, the renal loss of water is decreased by some mechanism additional to tubular water reabsorption. It seems justifiable to suspect that this mechanism is a decrease 
in the rate of glomerular filtration. First, the results of Dicker obtained in this laboratory suggest a correlation between urine volume and glomerular filtration rate in the infant rat; and secondly, the occurrence of a substantial fall in the volume of glomerular filtrate is a well known response in adult men and in dogs suffering from advanced dehydration, i.e. from a degree of water loss which produces haemoconcentration and a decrease of the blood volume (Smith, 1937; Kenney, 1949.) A defence mechanism which operates in all age groups would thus also be invoked in the newborn animals but after much shorter periods of fluid deprivation than in adults. Significant reduction of the rate of glomerular filtration in infant rats during the first 24 hours of fluid withdrawal is also suggested by the observation that, unlike in the adult animals in which potassium excretion was increased, the renal elimination of potassium fell to about half of the normal value and that, again in contrast to the adult controls, their plasma urea had markedly increased (Fig. 4) at a stage when that of normal infant rats begins to fall. A considerable rise of plasma

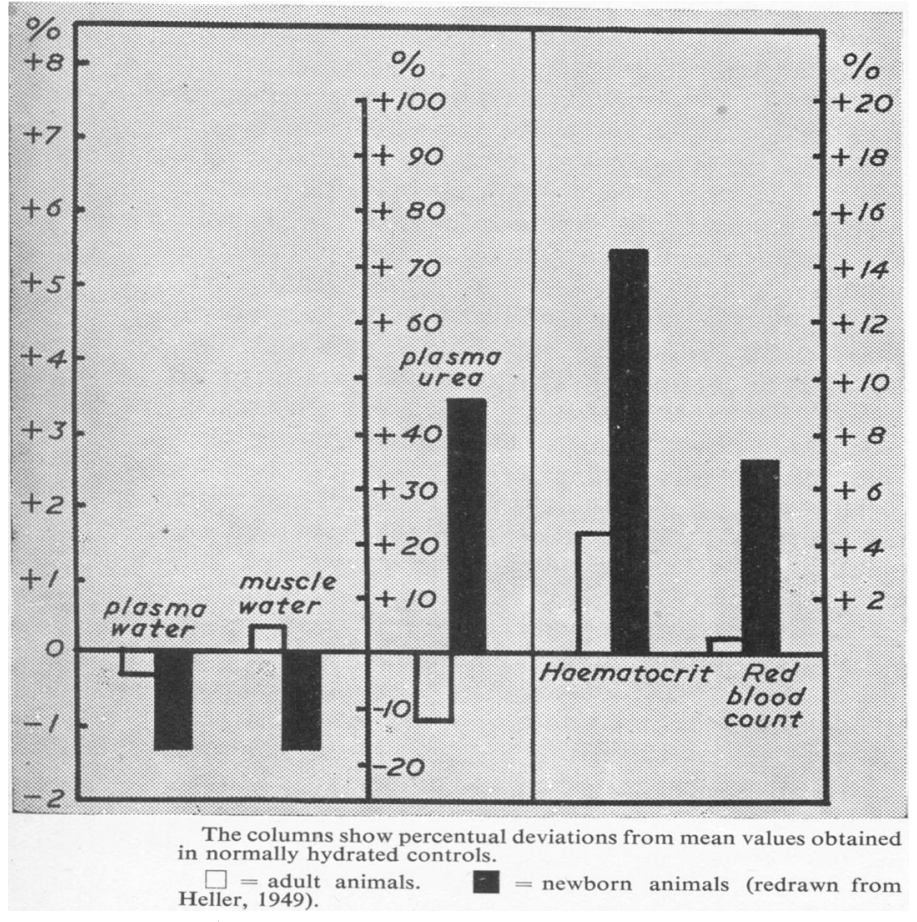

FIG. 4.-Effects of withdrawing fluid and food for 24 hours from adult and newborn rats. osmotic pressure in the dehydrated newborns seems therefore likely, and the highly interesting experiments of McCance and Wilkinson (1947) have shown how badly fitted the kidney of newborn rats is to cope with abnormal osmotic load. These authors administered hypertonic sodium chloride solutions to adult and to newborn rats, but while the adult animals responded by reducing the osmotic pressure of their urine and by producing a large diuresis which enabled them to excrete $27 \%$ of the electrolytes in five hours, newborn rats given a similar dose responded by raising the urinary osmotic pressure but failed to produce a diuresis and excreted only $6 \%$ of the test dose in the same time. Hypertonic solutions of urea produced effects similar to those of sodium chloride in both the adult and the newborn rats.

To sum up: newborn rats deprived of water for 24 hours were unable to economize body water by concentrating the urine to the same extent as adults. Some economy in water excretion was probably achieved by a decrease in the glomerular filtration rate but at the price of the retention of certain crystalloids. In contrast to the adults, their plasma and tissue solids were found to be significantly increased as were the haematocrit values and the red cell count (Fig. 4). These findings show, therefore, that the defence of newborn rats against dehydration was less effective than that of adult animals under comparable conditions of stress, i.e. the internal environment of the adults deviated less from the normal.

The response of newborn infants to fluid restriction shows certain similarities to that of newborn animals. Accumulation of electrolytes and urea in the plasma of dehydrated infants has been described by numerous authors (Kerpel-Fronius, 1932, 1940; Young, Hallum, and McCance, 1941; Rapoport, 1947; Smith, Yudkin, Young, Minkovski, and Cushman, 1949) but it is not easy to deduce from these investigations to what degree the response of infants differs from that of adults under quantitatively comparable conditions of this kind of stress. It appears from the carefully controlled experiments of Dean and McCance (1949) that newborn infants are less capable of disposing of excessive osmotic loads than are adults. In parallel to the experiments on newborn rats, which have already been described, Dean and McCance administered hypertonic sodium chloride or urea solutions to adults and newborns after 15 hours of fluid deprivation. The adult subjects responded with a rapid and extensive diuresis accompanied by a fall in the urinary osmotic pressure, but the urine flow in the newborn infants increased only slowly and to a very moderate degree, and a rise rather than a fall in the osmotic pressure of the urine was found. Certain well 
established features of the kidney function of newborn infants suggest an explanation for the differences observed. It is generally agreed (Young and McCance, 1942; Dean and McCance, 1947; West, Smith, and Chasis, 1948; Barnett, Hare, McNamara and Hare, 1948; Rubin, Bruck, and Rapoport, 1949) that the rate of glomerular filtration is much lower in infants than in adults, though there is no unanimity as to the closeness of the relationship between the glomerular filtration rate and the minute volume of urine (Barnett, Perley, and McGinnis, 1942; Young and McCance, 1942; Barnett et al., 1948; Dean and McCance, 1949; Tudvad and Vesterdal, 1949). The clearances of urea, chloride, sodium, and potassium are low. It is justifiable to assume that the low glomerular filtration rate accounts partly for the low clearances but there is as yet insufficient evidence available to state to what extent renal tubular factors are participating. That is to say, it is not known whether the tubules reabsorb more of the filtered crystalloids in infancy than they do in adult life. This appears to happen in the case of chloride in newborn infants (Dean and McCance, 1949), and is likely to apply to other crystalloids, not necessarily because of a difference in the reabsorbing capacity of the tubular epithelium but perhaps, as suggested by Pitts and Duggan (1950), from their results on sodium absorption in adult men and dogs, because a lowered rate of glomerular filtration increases tubular reabsorption.

Although sodium and chloride seem to be excreted in a similar manner, recent work suggests that potassium excretion requires special consideration. Potassium is normally filtered and partially reabsorbed (Winkler and Smith, 1942; Dicker, 1948) but in certain conditions, for instance in chronic glomerulo-nephritis in men, some potassium is apparently secreted by the tubules (Berliner and Kennedy, 1948; Mudge, Foulks, and Gilman, 1948; Leaf and Camara, 1949). Another condition which provokes potassium secretion, at least in rats is, according to Dicker (1951), dehydration. This observation may explain a finding which had already been mentioned, namely the depression of the potassium excretion in dehydrated (and starving) infant rats which was in marked contrast to the rise of potassium elimination in adult controls. Tubular secretion would easily remove any potassium released by the breakdown of tissues in the adult animal while increased absorption due to low glomerular filtration in the dehydrated newborn could not be compensated because of immaturity of the secretory mechanism. The capacity for tubular secretion of para-amino hippurate and diodone has so far not been investigated in newborn rats, but there is general agreement (Dean and McCance, 1947; West et al., 1948; Rubin et al., 1948; Barnett et al., 1948) that it is lower in newborn infants than in adults. It would also seem (Dean and McCance, 1947; Brod and Sirota 1948) that the secretory mechanism for creatinine, i.e. for an endogenous substance, is not fully developed in infants. A generalized immaturity of tubular secretory function in newborns is thus strongly suggested.

It will be remembered that another feature which distinguished the response of newborn rats from that of adult animals to dehydration consists in the apparent inability to concentrate their urine to the same degree as the adult. What is the concentrating ability of dehydrated newborn infants ? A study of the specific gravity and osmotic pressure of urine samples obtained from normal newborn infants during the first days after birth shows immediately that their kidney is a more mature organ than that of newborn rats. The range of osmotic pressure values is very much wider; that is to say, in spite of the similar nature of their food, infants both dilute and concentrate their urine much better than newborn rats. In fact, measurements obtained during the first 48 hours, i.e. during the period of 'physiological hydropenia' show that slightly hypertonic urines can be elaborated by normal infants (Heller, 1944). Values of $450 \mathrm{~m}$. osmol./1. and over were obtained and urines of still higher concentration can be prepared, when the dehydration of the newborns is intensified. Smith and his colleagues (1949) who investigated premature babies after periods of fluid (and food) deprivation lasting from 52 to 112 hours obtained values up to $624 \mathrm{~m}$. osmol./1. and the findings of Barnett et al. (1948) point in the same direction. But can infants produce urines as concentrated as adults? The mean concentration of urines from normally hydrated healthy subjects in Heller's (1944) series was $900 \mathrm{~m}$. osmol. and considerably higher figures (up to $1,300 \mathrm{~m}$. osmol./1.) have been obtained when adult subjects underwent a short period of water deprivation.

Why does the kidney of newborn infants and animals appear to be unable to concentrate the urine to the same extent as adults ? The question is clearly of considerable complexity but here only some endocrine aspects will be briefly discussed.

It is generally agreed that the posterior pituitaryrenal mechanism constitutes the major determinant of the final urinary concentration in normal adults. The inability of the kidney of the newborn to concentrate suggests a possible inadequacy of this mechanism at birth. There can be little doubt that both in hydropenic infants and in dehydrated newborn animals the adequate physiological stimulus 


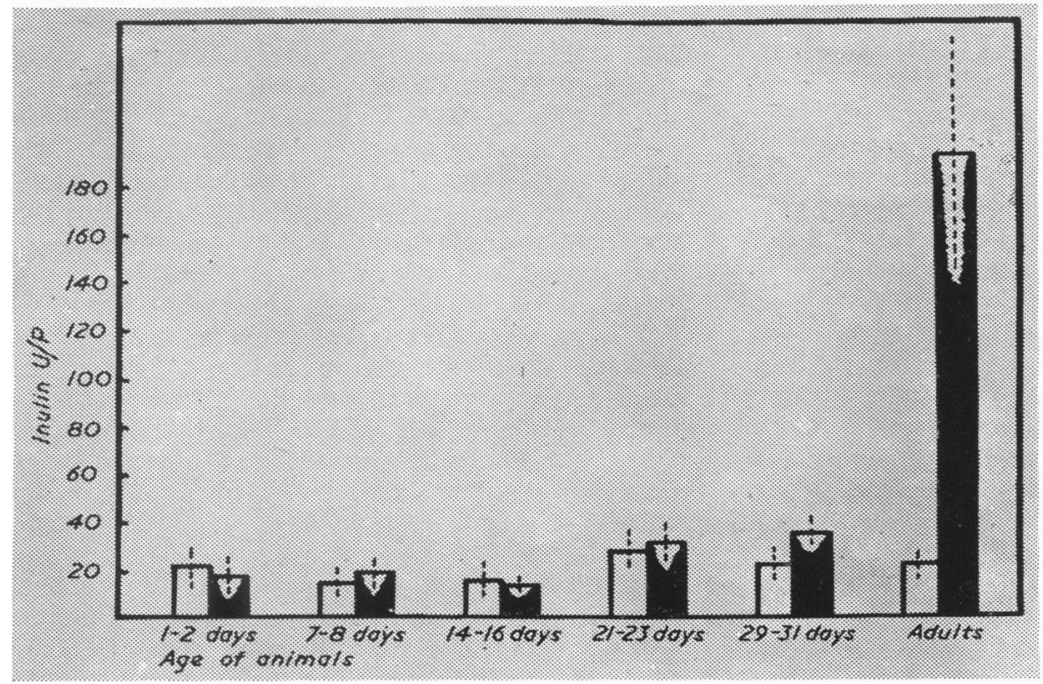

$\square=$ mean inulin $\mathrm{U} / \mathrm{P}$ ratios $145 \frac{\square}{\bar{\sigma}}$ minutes after the administrations of $4.5 \mathrm{ml}$. water $/ 100 \mathrm{~g}$. by stomach tube.

$=$ mean inulin $U / P$ ratios $145 \underline{\bar{Q}}$ minutes after the same amount of water and the injection of $10 \mathrm{mU}$. vasopressin/ $100 \mathrm{~g}$. rat. The broken lines indicate twice the standard error.

FIG. 5. Effect of posterior pituitary antidiuretic hormone on $\overline{\bar{\sigma}}$ inulin urine/plasma ratios in rats. $\frac{\mathrm{T}}{7}$ A small but significant response $\mathbb{\mathbb { D }}$ will be noted in the rats aged $4 \stackrel{\omega}{\infty}$ weeks. The renal response to the antidiuretic hormone at this age $\overrightarrow{0}$ is, however, clearly much less:developed than in the adult $\vec{\omega}$ animals (Heller, unpublished experiments).

for an increased secretion of the posterior pituitary antidiuretic hormone (Verney, 1948), namely an increase of plasma osmotic pressure, is present. However, there is the possibility that the hypothalamic structures concerned with this regulatory mechanism are too immature to transmit it, or that the gland elaborates insufficient amounts of the antidiuretic hormone, or again that the kidney of the newborn is less sensitive to it than the adult organ. The second possibility, i.e. lack of antidiuretic hormone, may conceivably apply in rats since it has been shown (Heller, 1947b) that the pituitary gland of the newborn of this species contains only about one-tenth of the antidiuretic principle in the glands of adult animals. It is less likely to apply to newborn infants: a recently completed series of estimations of the antidiuretic hormone content of the posterior lobe of newborn infants (Heller and Zaimis, 1949) showed that these glands, though containing per $\mathrm{mg}$. only about one-fifth of the activity of adult posterior pituitary tissue, contained all the same several hundred milliunits of the antidiuretic principle. There is evidence (Heller, unpublished experiments) on the other hand, that the renal tubules of newborn rats are less sensitive to the antidiuretic hormone than those of adults (Figs. 2 and 5) and the same appears to apply to newborn infants. It will be seen from Fig. 6, for instance, that after the intramuscular injection of a large dose of posterior pituitary extract the osmolar concentration of the urine of an infant increased to more than twice the initial value.

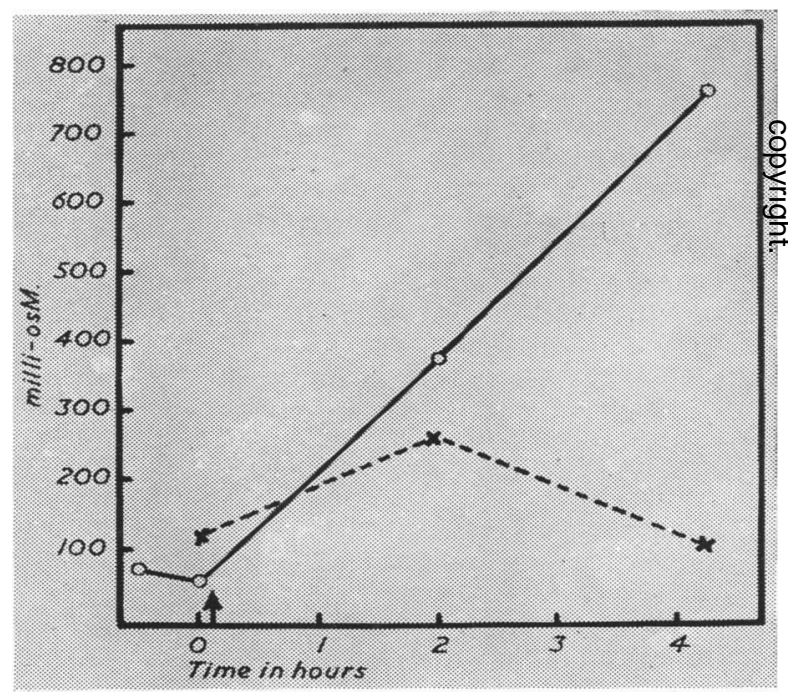

Fig. 6.-Comparison between the effect of equivalent doses of posterior pituitary extract on the urinary osmotic pressure (in terms of milli-osmolar equivalents) of an infant aged 5 days $(X-\ldots-X)$ and of an adult control $(O-O)$. At the time marked by the arrow intramuscular injection of $\mathbf{0 . 2 5} \mathrm{U}$. of posterior pituitary extract per sq. $\mathrm{m}$. body surface. Absolute doses= $0.05 \mathrm{U}$. and $0.5 \mathrm{U}$ respectively. It will be noted that the initial osmolar concentration is much the same in both subjects (Heller, 1944). 
However, the same dose given to an adult control caused not only much higher urinary concentrations but showed also a much longer duration of the antidiuretic effect. Barnett and his colleagues (1948) using a difference technique (determinations of inulin U/P ratios) found likewise a considerable response to large intravenous doses of vasopressin in premature infants. They concluded that their results 'indicated a good response of the tubules of the premature infant to antidiuretic hormone.' They failed, however, to control their findings by comparable experiments on adults. Unfortunately, therefore, their results cannot be used for a quantitative assessment of differences between the responses of the neonatal and adult kidney.

Low sensitivity to the posterior pituitary antidiuretic hormone found in newborn infants may have some bearing on a pathological condition of older children and adults which had been termed 'nephrogenic' or 'vasopressin-resistant' diabetes insipidus. Infants suffering from this 'disease' are popularly known as 'water babies'. Recently published cases (Forssman, 1945; Williams and Henry, 1947; Dancis, Birmingham, and Leslie, 1948) show that we are dealing with a congenital and usually a hereditary defect. It seems likely that the renal tubules in such individuals fail to reach normal maturity. The apparently complete absence of an antidiuretic response to large doses of 'pitressin' (Dancis et al., 1948) suggests moreover that the developmental deviation occurs some time before birth as normal full-term infants show at least a partial response to the antidiuretic hormone (Heller, 1944). Whether the renal abnormality is an anatomical defect or a failure to develop the biochemical substrate for the distal tubular transfer mechanism of water or both is an open question. It seems preferable to restrict the term diabetes insipidus to cases where insufficient secretion of the posterior pituitary hormone has been demonstrated and to regard the condition just described a separate pathological entity.

Were we concerned with adults, a discussion of other endocrine influences on the water metabolism would follow, and particularly the effects of adrenocortical and anterior pituitary extracts would have to be considered. A beginning in the investigation of the function of these glands in the newborn has admittedly been made (Moon, 1940; Jailer, 1950; King and Mason, 1950), but the data are as yet too scanty to warrant even tentative conclusions.

This serious gap may serve to emphasize the lack of experimental evidence in this field of neonatal research. We have, one feels, merely reached the stage where the differences between the water and mineral metabolism of the adult and newborn are beginning to be more clearly defined. The analyses of these differences and the evaluation of their clinical importance are to a very large extent a thing of the future.

\section{REFERENCES}

Adolph, E. F. (1943). 'Physiological Regulations.' Lancaster, Pennsylvania.

Alexander, M.B. (1948). Brit. med. J., 2, 973.

Arnott, G. M., and Young, W. F. (1942). Lancet, i, 523. Aschenheim, E. (1919). Z. Kinderheilk., 24, 281.

Barnett, H. L., Hare, K., McNamara, H., and Hare, R. (1948). J. clin. Invest., 27, 691.

Perley, A. M., and McGinnis, H. G. (1942). Proc. Soc. exp. Biol..N.Y., 49, 90.

Berliner, R. W., and Kennedy, T. J. (1948). Ibid., 67, 542.

Brod, J., and Sirota, J. H. (1948). J. clin. Invest., 27, 645 .

Brody, E. B. (1943). Amer. J. Physiol., 139, 230.

Clark, W. G. (1939). Proc. Soc. exp. Biol. N. Y., 40, 468.

Dancis, J., Birmingham, J. R., and Leslie, S. H. (1948). Amer. J. Dis. Child., 75, 316.

Dean, R. F. A., and McCance, R. A. (1947). J. Physiol., Lond., 106, 431

Ticl, (1949). Ibid., 109, 81.

Dicker, S. E. (1948). Ibid., 107, 8 .

(1950). Biochem. J., 46, 53.

(1951). Science, 113, 187.

and Heller, H.' (1951). J. Physiol., Lond., 112, 149.

(1946). Brit. J. exp. Path., 27, 158

Elkinton, J. R., and Taffel, M. (1942). J. clin. Invest., 21, 787.

—, and Winkler, A. W. (1944). Ibid., 23, 93.

$\overline{\text { Finkelstein }}, \frac{1}{\mathrm{H}}$ a Danowski, T. S. (1948). Ibid., 27, 74. krankheiten,' 4th ed. Amsterdam.

Forssman, H. (1945). Acta Med. Scand., Suppl. 159.

Gaisford, W., and Schofield, S. (1950). Brit. med. J., $1,1404$.

Gamble, J. L. (1947). ' Chemical Anatomy, Physiology and Pathology of Extracellular Fluid.' 5th ed. Harvard Univ. Press.'

Gaunt, R. (1944). Endocrinology, 34, 400.

Hallum, J. L. (1941). 'Oedema Neonatorum,' M.D. Thesis. University of St. Andrews. Cited by Young, Hallum, and McCance (1941).

Heller, H. (1944). J. Physiol., Lond., $102,429$.

(1947a). Ibid., 106, 245.

(1947b). Ibid., 106, 28

(1949). Ibid., 108, 303.

, and Smirk, F. H. (1932a). Ibid., 76, 1.

, (1932b). Ibid., 76, 23.

-, and Zaimis, E. J. (1949). Ibid., 109, 162.

Herrington, L. P. (1940). Amer. J. Physiol., 129, 123.

Jailer, J. W. (1950). Endocrinology, 46, 420.

Joseph, S., Schweizer, M., Ulmer, N. Z., and Gaunt, R. (1944). Ibid., 35, 338.

Kenney, R. A. (1949). Acta med. Scand., 135, 172.

Kerpel-Fronius, E. (1932). Mschr. Kinderheilk., 51, 400. (1940). Ibid., 81, 294.

King, N. B., and Mason, H. L. (1950). J. clin. Endocrinol., 10, 479.

Krause, F. (1928). Z. Biol., 87, 167.

Lasch, W. (1923). Z. Kinderheilk., 36, 42.

Leaf, A., and Camara, A. A. (1949). J. clin. Invest., 28, 1526. 
McCance, R. A., and Wilkinson, E. (1947). J. Physiol., Lond., 106, 256.

Moon, H. D. (1940). Proc. Soc. exper. Biol. N.Y., 43, 42.

Mudge, G. H., Foulks, J., and Gilman, A. (1948). Ibid., 67, 545.

Nadal, J. W., Pedersen, S., and Maddock, W. G. (1941). J. clin. Invest., 20, 691.

Pitts, R. F., and Duggan, J. J. (1950). Ibid., 29, 372.

Rapoport, S. (1947). Amer. J. Dis. Child., 74, 682.

Rietschel, H. (1934). Ergebn. inn. Med. Kinderheilk., 47,185

Rubin, M. I., Bruck, E., and Rapoport, L. M. (1949). $J$. clin. Invest., 28, 1144.

Smith, C. A., Yudkin, S., Young, W., Minkovski, A., and Cushman, M. (1949). Pediatrics, 3, 34.
Smith, H. W. (1937). ' The Physiology of the Kidney.' New York.

Tudvad, F., and Vesterdal, J. (1949). Acta paediatr., Stockh., 37, 429.

West, J. R., Smith, H. W., and Chasis, H. (1948). Pediat., 32, 10.

Williams, R. H., and Henry, C. (1947). Ann. intern. Med., 27, 84.

Winkler, A. W., and Smith, P. K. (1942). Amer. J. Physiol., 138, 94.

Verney, E. B. (1948). Brit. med. J., 2, 119.

Young, W. F., Hallum, J. L., and McCance, R. A. (1941). Archives of Disease in Childhood, 16, 243

Young, W. F., and McCance, R. A. (1942). Ibid., 17,65 . 